\title{
A Comparative Study of Adjustment among Day Scholars and Hostel Students
}

\author{
Chinky Upadhyaya ${ }^{1 *}$
}

\section{ABSTRACT}

The purpose of the study was to find out the differences in adjustment among Day Scholars and Hostel students who are adolescents in age range (14 to 15 years). From Meerut District, in Uttar Pradesh state. 600 School students were selected by random sampling method .Sample consists of 300 Day Scholars (150 males and 150 Females) and 300Hostel students (150 males and 150 Females). The age range was 14 to 15 years. The data was collected with the help of Bell 's adjustment inventory. Obtained data were statistically analyzed by Mean, SD and T test. Results revealed that Day Scholars and Hostel students differed significantly on home, health, social, emotional and overall adjustment.

\section{Keywords: Adjustment, Day Scholars — Hostel students and Adolescents}

The concept of adjustment is as old as human race on earth. The process of adjustment starts from the birth of child and continuous till his death. Psychologists use term "adjustment "varying conditions of social or interpersonal relationship in the society. Adjustment means reaction to the demands and pressures of social environment imposed upon the individual. The demand may be external or internal to whom the individual reacts (Agarwal 1996). In this rapid changing, adjustment is a persistent feature of human personality. A man of adjusting nature can lead a cheerful and wholesome life.

Residential care has a great impact on personality development. Some researchers has observed that boarding school experiences results in to many problems of which most prominent is emotional disorder Bronfenbrenner, (2007) reported that as compared to boarders bear high risk of adapting unhealthy habits. Research findings had proved that there is a positive association between factors relating to residential condition, status and children's unhealthy personality. Investigative the special effects of boarding schools on teenagers it was found that Forty- nine percent of the students suffered from social impairment and mood disorder. Cohen, A. B.,

\footnotetext{
${ }^{1}$ MA., M.PHIL. (UGC NET), Department of Psychology, Ch.Charan Singh University, Meerut, India *Responding Author

(C) 2016, C Upadhyaya; licensee IJIP. This is an Open Access Research distributed under the terms of the Creative Commons Attribution License (http://creativecommons.org/licenses/by/2.0), which permits unrestricted use, distribution, and reproduction in any Medium, provided the original work is properly cited.
} 


\section{A Comparative Study of Adjustment among Day Scholars and Hostel Students}

Pierce, J. D., Chambers, J., Meade, R., Gorvine, B. J., \& Koenig, H. G.(2005). Though boarding school administration had taken few measures in terms of altering the prevailing environment, which proved to be helpful to lessen the rate of disordered personality among the students, but in the long run it was unable to eliminate the adverse effect of boarding school. ${ }^{3}$ Studies in 1994 reported that among boarders lack of emotional expression is very much evident which later on converts into problematic behavior such as feeling of inadequacy, restiveness, antagonism violence and egocentricity. Comparing the level of social adjustment, significant difference was reported, as hosteller exhibited less sociability. With reference to level of personality incorporation integration hostlers showed less personality integration as s compared to day scholar The personality of hostlers and non hostler was investigated founding that there was significant difference between both group on major dimensions of the personality Day scholars are proved to be healthier (physically and emotionally) and especially posses better self concept than boarders Boarders students exhibited lower scores on determinants of ego identity, self esteem. For boarders homesickness is said to be a normal developmental process of place identity Boarders suffer from the problems of absorption in different living setup which results into poor academic performance and emotional maladjustment. Bergin, A (1983). Day scholars does have an advantage in shielding the child from the adverse effects of peer pressure and its resulting problems. From kindergarten to high school children are faced with choices that they are forced to make to be part of a group. From seemingly insignificant choices like preferring a cartoon character over another to obviously serious ones involving drugs and alcohol, physical intimacy with the opposite sex and even neglecting studies, effect a child's thinking pattern and personality. While hostlers are exposed to these pressures on a daily basis, a student who is day scholar can be provided with a strong foundation where the child is made aware of the consequences of these choices before being exposed to them. In short, day scholars re more likely to develop a strong sense of self as opposed to the boarders Brown, D. R., \& Gary, L.E. (1994.). Boarder's students exhibited lower scores on determinants of ego identity, self esteem. For boarders homesickness is said to be a normal developmental process of place identity Boarder's suffer from the problems of absorption in different living setup which results into poor academic performance and emotional maladjustment. On the hand in a home s environment a child gets the undivided attention of the parent/teacher and thus is able to overcome and comprehend academic issues at a deeper level as well as afasterpace. Bronfenbrenner, (2007)) Enochs and Roland (2006) examined the relationship between living environment, gender, overall adjustment to college and social adjustment in freshmen's academic and overall adjustments. The study found that day scholars had significantly higher overall adjustment levels than hostlers. The process of adjustment .starts from the birth of child and is continuous till his death. Psychologists use term "adjustment "varying conditions of social or interpersonal relationship in the society. Adjustment means reaction to the demands and pressures of society

environment imposed upon the individual. The demand may be external or internal to whom the individual is to react (Agarwal, 1996). 


\section{A Comparative Study of Adjustment among Day Scholars and Hostel Students}

According to Carter V. Good (1959), "Adjustment is the process of finding and adopting modes of behaviour suitable to the environment or the changes in the environment". Erickson (1968) Adolescents as a good have long been regarded searching for themselves to find some form of identify and meaning in their lives. The Gale encyclopedic of childhood and adolescence sometimes referred to as teenage years. Youth puberty, adolescence covers the period from roughly as 10 to 20 in a child's development. The word adolescence is Latin in origin, derived from the verb adolescent, which means "to grow into adulthood. "In all societies, adolescence" is a time of growing up, of moving from the immaturity of childhood into the maturity of adulthood. In this study Day Scholar and Hostlers residence is considered. The Day Scholar and Hostlers areas have their own distinctive features and they differ predominantly with each other in terms of homogeneity, integrity, occupations, environmental differences, social traditions, differences in size of communities, differences in physical facilities and educational level. Day Scholar and Hostlers residence also differentiated on the basis of psychological attributes. For instance the behaviour patterns, thoughts, beliefs and ideologies, patterns of socialization, social cohesion, emotional bonding, simplify and sincerity of relationships. Day Scholar Life is fast and stressful as compared to Hostlers life. Those adolescents residing Day Scholar or Hostlers areas are socialized and natured totally different situations. So it is expected that Day Scholar and Hostlers situation can affect adolescent's emotional intelligence and various areas of adjustment.

Chadda (1985) found that no difference was observed between the emotional adjustment scores of various sub groups of teachers, viz male female, Hostlers and urban. Chu (2002) revealed that males have higher level of emotional intelligence that the females. With regard to gender wise differences in adolescents, results are in contradiction with the findings of Abdullah and Maria (2008) who suggested that male students' overall level of adjustment was found to be as compared to female students. Gupta (1990) found that, adolescent gir1s studying in Day Scholar schools were significantly better in their social adjustment as compared to girls in Hostlers schools. Gupta, Sushma (1990) found that parents of girls studying in Day Scholar and English medium schools had a better opinion regarding the social adjustment of their daughter as compared to the parents of girls in Hostlers and Hindi medium schools adolescent girls studying in Day Scholar schools were significantly better in their social adjustment as compared to girls in Hostlers schools. Kaur (2007) stated that males were high on home, health, social and total adjustment. Kumari (1988) found that sports girls belonging Hostlers and Day Scholar areas were better in emotional social and educational adjustment than non sports girls. Pandey (1979) found that among students of higher secondary stage, the Hostlers group to be better in emotional, health and school adjustment where as the Day Scholar group to be better in aesthetic adjustment significant relationship exists among adjustment, aspiration and achievement Wing and Love (2001) reported that Day Scholar adolescents had comparatively better emotional intelligence and adjustment against Hostlers counterparts. Sujatha, Gaonkar, khadi and Katarki (1993) found significant differences in the adjustment of day scholars and Hostlers. 


\section{METHOD}

\section{Sample:}

Present research has been conducted in Meerut District of Uttar Pradesh 600 students of $9^{\text {th }}$ and $10^{\text {th }}$ class have been selected by random sampling method for this research.. Students studying in $9^{\text {th }}$ and $10^{\text {th }}$ class were selected on the basis of gender and residence. The age range from 14 to 15 years

\section{Tool:}

Bell's Adjustment Inventory: This inventory is developed by R. K. Ojha (1994). This inventory includes four parts - home. health, social and emotional. Each part has 35 statements which are answered 'Yes' or 'No'. Scoring of inventory is most easy. The 'yes' response are counted. For each 'yes' response 1 score is to be given. The total number of 'yes' scores thus makes total score of the individual in the part. It is a negative inventory. When an individual answers in 'yes', it indicates his difficulties. Reliability is reported to be 0.85 which is very high. Validity of this inventory is above 0.75 . High score on this inventory denotes unsatisfactory adjustment.

\section{Hypothesis :}

1. There will be no significant difference between day scholars and hostel students on home adjustment.

2. There will be no significant difference between day scholars and hostel students on health adjustment.

3. There will be no significant difference between day scholars and hostel students on social adjustment.

4. There will be no significant difference between day scholars and hostel students on emotional adjustment.

5. There will be no significant difference between day scholars and hostel students on overall adjustment.

\section{Objectives :}

The objective of present study was to find out the differences in adjustment among day scholars and hostel students.

\section{RESULTS AND DISCUSSION}

Table 1: Mean, SD and 't' value of various areas of adjustment of Day Scholar and Hostlers adolescents $N=420$

\begin{tabular}{|l|l|c|c|c|c|}
\hline \multicolumn{1}{|c|}{$\begin{array}{c}\text { Area of } \\
\text { adjustment }\end{array}$} & \multicolumn{1}{|c|}{$\begin{array}{c}\text { Place of } \\
\text { residence }\end{array}$} & Mean & S.D. & SE Mean & t \\
\hline \multirow{2}{*}{ Home } & Day scholars & 14.38 & 5.08608 & .24847 & $2.64^{* *}$ \\
\cline { 2 - 5 } & $\begin{array}{l}\text { Hostel } \\
\text { Students }\end{array}$ & 15.28 & 5.08608 & .23422 & \\
\hline
\end{tabular}

(c) The International Journal of Indian Psychology, ISSN 2348-5396 (e)| ISSN: 2349-3429 (p) | 125 
A Comparative Study of Adjustment among Day Scholars and Hostel Students

\begin{tabular}{|l|l|c|c|c|c|}
\hline \multicolumn{1}{|c|}{$\begin{array}{c}\text { Area of } \\
\text { adjustment }\end{array}$} & $\begin{array}{c}\text { Place of } \\
\text { residence }\end{array}$ & Mean & S.D. & SE Mean & t \\
\hline \multirow{2}{*}{ Health } & Day scholars & 10.56 & 4.83986 & .27941 & \multirow{2}{*}{$2.02^{*}$} \\
\cline { 2 - 5 } & $\begin{array}{l}\text { Hostel } \\
\text { Students }\end{array}$ & 11.39 & 5.71933 & .30295 & \\
\hline \multirow{2}{*}{ Eocial } & Day scholars & 18.80 & 6.26008 & .17362 & \multirow{2}{*}{$2.26^{*}$} \\
\cline { 2 - 5 } & $\begin{array}{l}\text { Hostel } \\
\text { Students }\end{array}$ & 19.43 & 3.55387 & .21881 & \\
\hline \multirow{2}{*}{$\begin{array}{l}\text { Overall } \\
\text { adjustmenal }\end{array}$} & Day scholars & 14.33 & 4.52149 & .31483 & \multirow{2}{*}{$3.02^{* *}$} \\
\cline { 2 - 5 } & $\begin{array}{l}\text { Hostel } \\
\text { Students }\end{array}$ & 15.71 & 6.44432 & .32862 & \multirow{2}{*}{$3.36^{* *}$} \\
\cline { 2 - 5 } & Day scholars & 58.08 & 6.79056 & .77298 & \\
\hline
\end{tabular}

${ }^{*} \mathrm{p}<005 .{ }^{* *} \mathrm{p}<0.01$

Table 1 shows that the mean value and SD value of Day Scholar adolescents on home adjustment is 14.38 and 5.08,respectively .Similarly mean value of Hostlers adolescents is a 15.28 and SO is 4.84. It's ' $t$ ' value is 2.64.lt is significant at 0.0 ] level. So the null hypothesis I, is rejected. It means that Day Scholars and Hostel Students differ on home adjustment. Day Scholars are more adjusted than Hostlers.

Regarding health adjustment mean values of Day Scholar and Hostel students are 10.56 and 11.39 respectively. Similarly their SD values are 5.72 and 6.26 respectively. It's 't' value is 2.02.It is significant at 0.05 level. . So the null hypothesis 2, is rejected. It means that Day Scholar and Hostel students differ on home adjustment. Day Scholars are better adjusted than Hostel students Mean and SD value of Social adjustment of Day Scholar is 18.80 and 3.55, and Hostel students mean and SD is 19.43 and 4.52 respectively. It's 't' value is 2.26. It is significant at 0.05 level. So the null hypothesis 3, is rejected. It means that Day Scholars and Hostel students are differ on home adjustment. Day Scholars are more adjusted than Hostel students.

Regarding emotional adjustment mean value of Day Scholars is 14.33 and SD value is 6.44.Similarly mean value of Hostel students is 15.77 and SD is 6.79. lt's 't' value is 3.02.lt is significant at 0.01 level. So the null hypothesis 4 , is rejected. It means that Day Scholars and Hostel students differ on home adjustment. Day Scholars are more adjusted than Hostlers.

Table no. 1, shows that overall adjustment mean of Day Scholars is 58.08 and SD is 15.82, whereas mean of Hostel students is 61.83 and SD is 16.60 . The ' $t$ ' value is 3.36. It is significant at 0.01 level. It means that Day Scholars and Hostel students differ on home, health social, emotional and overall adjustment. So the null hypothesis is rejected. There is difference between

(C) The International Journal of Indian Psychology, ISSN 2348-5396 (e) | ISSN: 2349-3429 (p) | 126 


\section{A Comparative Study of Adjustment among Day Scholars and Hostel Students}

Day Scholars and hostel students on home environment health awareness, social perception and opportunities, way of expression of feelings. Results show that Day Scholars and Hostlers significantly differ on home, health, social emotional and overall adjustment. Day Scholars have better adjustment than Hostel students Previous research of Wing and Love (2001) supporting this findings. Shah (1989) also found that Day Scholars had better adjustment than Hostlers.

\section{CONCLUSION}

It was found that Day Scholars and Hostel students significantly differ on home, health, social , emotional and overall adjustment. Day Scholars have more adjustment capacity than Hostel students.

\section{Acknowledgments}

The author appreciates all those who participated in the study and helped to facilitate the research process.

\section{Conflict of Interests}

The author declared no conflict of interests.

\section{REFERENCES}

Abdullah and Maria (2008). Contribution of Emotional Intelligence, Coping and social Support towards Adjustment and Academic Achievement amongst. Fresh Students in the University. Ph. D Thesis Unpublished University Putra Malaysia.

Aggrwal, J. C. (1996). Essentials of Educational Psychology. New Delhi Vikas publishing House Pvt. Ltd.

Berger, J.B. (1997). Students' sense of community in residence halls, social integration, and First-year persistence. Journal of College Student Development, 5 441-452

Bergin, A. Religiosity and mental health: A critical reevaluation and meta-analysis. Professional Psychology: Research and Practice.1983.vol14(2).170-184.

Bronfenbrenner, (2007) U. Reaction to social pressure from adults versus peers among Soviet day school and boarding school pupils in the perspective of an American sample. Journal of Personality and Social Psychology.2007.15 (3), 179-189

Brown, D. R., \& Gary, L.E. ( 1994.). Religious involvement and health status among AfricanAmerican Males. Journal of National Medical Association, 1994.vol 831, 86(11), 825-831

Carden, A.I., \& Feicht,R.(2000)Homesickness among American and Turkish College Students Journal of Cross-Cultural Psychology

Chadda, D.K.( 1985) Self concept of teachers and their emotional adjustment in 4th survey of research in Education by M.B. Buch (1983-88), N.C.E.R.T.

Enochs, W. K., \& Roland, C. B. (2006). Social adjustment of college freshmen: the importance of gender and living environment College Student Journal, 40(1), 


\section{A Comparative Study of Adjustment among Day Scholars and Hostel Students}

Gerdes, H., \& Mallinckrodt, B. (1994). Emotional, social, and academic adjustment of college students: A longitudinal study of retention Journal of Counseling \& Development, 72 (3), 281-288.

Good C.V (1959). Dictionary of Education. New York: McGraw Hill Book Company.

Kashinath, M. M.( 1990) Adjustment in Navodaya Vidyalayas. The progress of Education, 1, 8-11.

Koenig, H. G.(2005) Intrinsic and extrinsic religiosity, belief in the afterlife, death anxiety, and life satisfaction in young Catholics and Protestants. Journal of Research in Personality. 2005. 39(3), 307-324.

Kumari ( 1988) Sports Management by D.O. Rao ( 2006),APH publication, New Delhi.

Ojha, R.K. (1994). Bell's Adjustment Inventory. National Psychological Corporation, Agra, India

Sujatha, S., Gaonkar. V., Khadi, P.\& Katarki, P, A. (1993) Factors influencing adjustment among adolescents. Indian Psychological Review, 40( 1-2), 35-40

Wing and Love (2001). Elective Affinities and Uninvited Agonies: Mapping Emotions with significant others onto health, emotion. Social relationships and health series in affective science. New York: Oxford University Press.

How to cite this article: C Upadhyay (2016), A Comparative Study of Adjustment among Day Scholars and Hostel Students, International Journal of Indian Psychology, Volume 3, Issue 4, No. 63, ISSN 2348-5396 (e), ISSN: 2349-3429 (p), DIP: 18.01.108/20160304, ISBN: 978-1-36532518-2

(C) The International Journal of Indian Psychology, ISSN 2348-5396 (e)| ISSN: 2349-3429 (p) | 128 